\title{
perifèria
}

Número 20 (2), diciembre 2015

http://revistes.uab.cat/periferia

\section{Indígenas, campesinos y capitalismo: Una radiografía de San Juan Chamula, Chiapas}

\author{
Julieta Martínez - UAB- CONACYT México. ${ }^{1}$
}

\section{DOI: http://dx.doi.org/10.5565/rev/periferia.488}

\section{Resumen}

El objetivo de este artículo es recuperar una cuestión aparentemente culminada en la década de los años setenta, los estudios del campesinado mexicano desde el enfoque estructural marxista. El análisis de la cuestión agraria no es la novedad de la investigación, tampoco el establecer la coexistencia de distintos modos de producción, sino mostrar los nuevos escenarios en los que diferentes lógicas económicas se articulan y se transforman; considerando la actual reconfiguración del espacio rural en una comunidad indígena y campesina de Los Altos de Chiapas, México. Se trata de un análisis cuantitativo y cualitativo en el que se establece una agenda común metodológica conformada por dos campos intercalados constantemente: teórico y empírico.

Palabras clave: Modo de producción, campesinos, indígenas, capitalismo y México

\begin{abstract}
The following article seeks to revive a topic that seemed to have been concluded in the 70's, the study of the Mexican peasants from a Marxist-Structural perspective. The analysis of the agrarian issue, nonetheless, is not a novelty in this research, and neither it is the establishment of coexisting modes of production. This research seeks to show emergent sceneries in which different economic mechanisms are articulated and transformed, considering the current reconfiguration of rural spaces in a peasant community of Los Altos de Chiapas, in Mexico. It is a quantitative and qualitative analysis in which a common methodology is used by mixing two fields: the theoretical and the empirical.
\end{abstract}

Keywords: Modes of Production, peasants, indigenous people, capitalism, Mexico

San Juan Chamula es uno de los municipios indígenas con mayor densidad poblacional de Mèxico. Especializado en el sector agrario es también el sexto municipio más pobre de Chiapas. Según datos del Censo Agropecuario y Ganadero

\footnotetext{
${ }^{1}$ Enviar correspondencia a: Julieta Martínez: julma50@hotmail.com
} 


\section{perifèria}

Número 20 (2), diciembre 2015

http://revistes.uab.cat/periferia

del 2007, el $95 \%$ de las familias de la comunidad realizan actividades agrícolas en $25,730.24$ hectáreas que representa más del $90 \%$ de la superficie disponible. Este municipio indígena y campesino nunca se ha correspondido con el ideal de comunidad cerrada de autoconsumo y autosuficiencia, debido a que históricamente se ha articulado con otras localidades vendiendo su fuerza de trabajo o sus mercancías. Chamula no es un municipio dominado por el capitalismo. Al interior de la comunidad se considera la vigencia de factores culturales, de parentesco y de religión que intervienen activamente en su organización social y económica.

Este trabajo parte de la tesis de que los mecanismos de transferencia y explotación de los campesinos son múltiples y que varían de acuerdo a las circunstancias históricas, al sistema político, a la estructura social y al grado de desarrollo de la economía capitalista. La pregunta central de este trabajo es la siguiente: ¿es el concepto de modo de producción el instrumento analítico apropiado para explicar las nuevas realidades del sector rural y los escenarios de confrontación de distintas sociedades? El objetivo general es recuperar una cuestión aparentemente culminada en la década de los años 70: los procesos de confrontación, integración y absorción de las economías no capitalistas por el sistema dominante.

El documento se presenta en tres apartados. Primero, se revisa la discusión teórica sobre la cuestión campesina de los años setenta; atendiendo la encrucijada metodológica en el estudio de comunidades campesinas e indígenas. Posteriormente se recupera el análisis marxista de campesinólogos mexicanos, planteando así nuestra nota metodológica de análisis. Por último, se presenta una monografía etnográfica de la zona de estudio, develando aspectos que validan el uso del instrumento analítico modo de producción concebido por Marx e interpretado y ajustado por Godelier \& Castaingts.

\section{Antecedentes}

A finales de la década de los sesenta y durante los setenta, tras la crisis agrícola y estallidos de movimientos campesinos, se produjo un gran auge de estudios dedicados a analizar los problemas del campo mexicano. Como menciona De Teresa (1996) o A. Bartra (2012), la discusión de esos años se centraba en entender los 


\section{perifèria}

Número 20 (2), diciembre 2015

http://revistes.uab.cat/periferia

procesos de subordinación de la producción campesina al modelo de acumulación del capital, y con ello el destino de los pequeños productores agrícolas en el contexto de la industrialización y modernización económica del país. El eje de la discusión era la coexistencia del modo de producción capitalista con el modo de producción campesino y la lucha de clases como resultado de las contradicciones inherentes a la base económica de la sociedad mexicana.

Entre los autores que abordaron la cuestión campesina se encuentran Wolf (1971\&1973), R. Bartra (1974, 1975,1977 \& 1982), A. Bartra (1979 a \& b ), Stevenhagen (1976), Diáz-Polanco (1976), Palerm (1976, 1978 \& 1980), Castaingts (1979), Warman (1972 \& 1980), entre otros. En sus aportaciones se referían al campesinado como un modo de producción distinto al capitalista, definiéndolo a través de una combinación peculiar de fuerzas productivas y relaciones de producción. La pobreza y la explotación del campesinado por el capitalismo eran los argumentos centrales que se encontraban en la mayoría de sus trabajos. En todos ellos se hacía énfasis en la escasa disponibilidad de los recursos productivos por parte de los campesinos como uno de los problemas centrales de la confrontación entre el campesinado y el sistema dominante. Warman (1980) afirmaba que tras los efectos de la reforma agraria, en la que se favoreció la expansión del capitalismo, el mundo rural mexicano solo se podía entender a través de la articulación orgánica y de dominación entre el modo de producción capitalista y el modo de producción campesino.

Stavenhagen (1969 \& 1976) \& Castaingts (1979) analizaron la subordinación del campesinado a la dinámica de las relaciones capitalistas utilizando la categoría teórica de modo de articulación. De acuerdo con ellos, en la articulación del campesinado con el capitalismo se incorporaba a la pequeña producción campesina al mercado capitalista y al mismo tiempo se advertía la heterogeneidad del agro mexicano. Castaingts (1979) señaló la coexistencia de dos sectores agrícolas en el campo mexicano, uno de empresarios agrícolas y otro de campesinos indígenas. El primero, moderno, caracterizado por crecientes inversiones de capital, alta tecnología y una producción orientada al mercado nacional e internacional. Y el otro, determinado por una escasa infraestructura productiva, una organización laboral de tipo familiar y una proporción ínfima de producción destinada al mercado 


\section{perifèria}

Número 20 (2), diciembre 2015

http://revistes.uab.cat/periferia

nacional. Para Stavenhaguen (1968 \& 1976) a partir de la coexistencia de estos dos sectores del campesinado mexicano se ampliaban los circuitos comerciales y de trabajo asalariado en la economía nacional. Así, la articulación del campesinado al capitalismo se materializaba a través de los mercados de fuerza de trabajo, de bienes y de dinero.

Respecto al devenir de los campesinos en un sistema dominado por la economía de mercado se cuestionó el planteamiento mecánico del desarrollo de las relaciones capitalistas y la desaparición progresiva de los modos de producción no capitalistas. Se criticó la tesis de la inevitable extinción de los campesinos. El argumento era que la economía campesina resultaba ser funcional a la dinámica de la acumulación capitalista; planteando la tesis de que lejos de desaparecer los campesinos, éstos se mantenían y se reforzaban. Con esta idea Warman (1980), Stavenhaguen (1976) \& Castaingts (1979) criticaron fuertemente el razonamiento de un desarrollo lineal de la economía, en el que se concibe a las economías indígenas como parte de una etapa pre-capitalista o pre-industrial.

En el marco de la discusión sobre el futuro de los campesinos, uno de los temas centrales era el instrumental teórico adecuado para estudiar a las economías campesinas considerando que en el caso de México también se trataba de comunidades indígenas. Se cuestionaba la pertinencia de usar las categorías clásicas de campesino y economía campesina propuestas por Lenin (1889), Chayanov (1974), Kroeber en 1948, Redfield (1930 \& 1948) \& Kochanowicz (1989) y se analizaba la pertinencia de definir al campesinado exclusivamente a través de la posesión y control de los medios de producción "tierra" y de su actividad productiva, puramente agrícola señalando su vinculación con el mercado capitalista.

En este sentido, Palerm (1978) planteó dos cuestiones que resultaron ser de vital importancia en el tratamiento de las economías campesinas indígenas en México. La primera, el rol del campesino indígena como productor directo y como fuerza de trabajo en el proceso de acumulación de capital. Y la segunda, de orden teórico y empírico, relacionada con la persistencia histórica de los modos de producción no capitalistas en un sistema dominado por el capitalismo. 


\section{perifèria}

Número 20 (2), diciembre 2015

http://revistes.uab.cat/periferia

Por su cuenta, Aguirre-Beltrán advirtió dos visiones en el estudio de los grupos indígenas en México. La primera, la visión culturalista que asignaba gran valor a las cuestiones de parentesco, religión y política. La segunda, de tendencia economicista que minimiza las cuestiones culturales. De acuerdo con Aguirre-Beltrán (1973), la articulación entre el sector indio y el sector mestizo nacional se debía plantear a través de la relación simbiótica en la que se complementan económicamente ambos grupos. Aguirre-Beltrán (1973) \& Stevenhagen (1976), recurrieron a la historia para explicar los procesos de incorporación de las comunidades indígenas campesinas a la economía nacional; centrando su atención en la política segregacionista dictada por el Estado.

En este trabajo la propuesta de recuperar el análisis a través de la lógica de la articulación de distintos modos de producción parte de la idea de que los mecanismos de transferencia y explotación de los campesinos son múltiples y que varían de acuerdo a las circunstancias históricas, al sistema político, a la estructura social y al grado de desarrollo de la economía capitalista. Nuestra hipótesis es que el concepto de modo de producción es un instrumento analítico que permite analizar y comparar los elementos esenciales de diferentes lógicas económicas. A través de esta categoría teórica se puede encontrar, comprender y asimilar la estructura base con la que funcionan las economías campesinas indígenas. Al mismo tiempo de que permite evidenciar las diferentes relaciones sociales, económicas y culturales que tienen lugar en el marco de contradicciones que resultan de la confrontación de distintos modos de producción.

\section{Nota metodológica, el concepto analítico modo de producción}

El método que se propone para analizar la coexistencia de distintos modos de producción en Sn Juan Chamula parte del estructuralismo marxista de la década de los setenta. La categoría teórica empleada en este trabajo no corresponde con el modo de producción asiático y tampoco con el modo de producción doméstico enunciado en la obra de Meillassoux (1975). La noción de modo de producción a la que nos referimos en esta investigación corresponde al desarrollado por Marx en el prefacio de la Critica a la Economía Política en 1859 y contiene las interpretaciones y los aportes que hizo Godelier (1974 \&1975), así como los ajustes propuestos por Castaingts (1979 \& 2012). Las aportaciones teóricas y analíticas que Godelier hizo 


\section{perifèria}

Número 20 (2), diciembre 2015

http://revistes.uab.cat/periferia

a la concepción original del modo de producción respecto a la plurifuncionalidad y jerarquización de las estructuras permite identificar y diferenciar el rol de la política, la religión y el parentesco en las relaciones sociales de producción. Los ajustes de Castaingts (2013) se refieren a los procesos administrativos y a los entramados de poder que resultan ser esenciales en las funciones de las relaciones sociales de producción de determinada sociedad.

De acuerdo con Godelier (1974) \& Castaingts (1979), el concepto modo de producción se construye a partir de la relación estrecha entre infraestructura y superestructura. Donde la infraestructura designa la combinación específica de cuatro aspectos: las condiciones ecológicas y geográficas, el desarrollo de las fuerzas productivas, las relaciones sociales de producción y el conjunto de representaciones sociales sobre el ecosistema y las fuerzas productivas. Las condiciones ecológicas y geográficas están dadas en una sociedad y es a partir de éstas que los hombres extraen los medios materiales necesarios para su existencia.

Las fuerzas productivas se refieren a los medios materiales e intelectuales que el hombre inventa y transforma constantemente para su aplicación en la creación de bienes y servicios. A través de las relaciones sociales de producción se determinan los mecanismos que permiten asegurar el acceso y el control social de las fuerzas productivas, la distribución y organización de la fuerza social del trabajo y, el reparto de los frutos obtenidos. Por último, el cuarto elemento de la infraestructura se refiere al conjunto de representaciones sociales del ecosistema y de las fuerzas productivas, así como la totalidad de los medios lingüísticos necesarios para expresarlos y comunicarlos. Es importante destacar la aplicación del concepto modo de producción como instrumento analítico no reside en su adecuación formal y estricta sino más bien en su construcción mediante el estudio de las estructuras sociales específicas.

\section{San Juan Chamula, una radiografía hecha a partir del concepto modo de producción}




\section{perifèria}

Número 20 (2), diciembre 2015

http://revistes.uab.cat/periferia

El orden de este apartado es el siguiente, en primer lugar, recurriendo a la historia, se presentan aspectos que han determinado la actual estructura socio-económica de Chamula. Posteriormente, se expone el análisis central del artículo a través de los elementos que conforman al concepto de modo de producción. La operatividad del instrumento analítico se divide en tres partes. En la primera se exploran las condiciones geográficas y ecológicas, haciendo notar el deterioro ecológico al que se enfrenta el municipio. En la segunda, se muestra el desarrollo de las fuerzas productivas y de las técnicas con las que cuenta la población para acceder a los medios materiales. En la tercera, se especifica al modo de producción dominante en la comunidad a través de los elementos de la infraestructura. En concreto, se atienden aquellos que intervienen en las funciones de las relaciones sociales de producción: las clases sociales, las estructuras de parentesco, religión y política. A lo largo del apartado se combinan los resultados de la exploración etnográfica con el análisis cuantitativo de los censos Agropecuarios y Ganaderos de 1991 y 2007.

San Juan Chamula es uno de los 18 municipios que conforman la región de Los Altos de Chiapas y donde el sector agrícola es la clave de la reproducción socio económico de la población. Chamula es la localidad indígena tzotzil-tzeltal de mayor densidad poblacional y con mayor interacción económica y política con el sistema capitalista. Sin embargo, es también el sexto municipio más pobre de Chiapas, con el $94.8 \%$ de su población en situación de pobreza. La localidad nunca se ha correspondido con el ideal de comunidad cerrada de autoconsumo y autosuficiencia, debido a que históricamente su población ha tenido que recurrir a otras tierras para poder subsistir, alquilándolas o trabajando en ellas. Así lo indican Wasserstrom (1980) \& Rus y Collier (2002), al señalar que desde mediados del siglo XIX Chamula dependía de la actividad económica en las tierras bajas del estado. La falta de tierra y la baja productividad agrícola resultó en crecientes flujos migratorios estacionales de chamulas hacia el valle central de la entidad, concretamente a las regiones de la Frialesca y el Soconusco (Bartra \& Otero, 1988). Lugares en los que rentaban parcelas de tierra para el cultivo de maíz y frijol o donde trabajaban como piones acasillados en la pizca del café.

Actualmente las condiciones socio-económicas de la población siguen siendo precarias. La crisis agrícola que afecta a toda la entidad ha empeorado 


\section{perifèria}

Número 20 (2), diciembre 2015

http://revistes.uab.cat/periferia

considerablemente los niveles de pobreza y bienestar de la población. Al día de hoy, los indígenas chamulas siguen buscando alternativas económicas fuera de los límites geográficos del municipio; vendiendo artesanías o su fuerza de trabajo.

a) Condiciones geográficas y ecológicas

El análisis del modo de producción en San Juan Chamula inicia con un elemento infraestructural de suma importancia, las condiciones ecologías y geográficas. Este apartado permitirá establecer el alcance de la principal actividad productiva de la comunidad: la agricultura; considerando las limitantes ecológicas a las que se enfrenta.

San Juan Chamula se halla a 2,260 metros sobre el nivel del mar en el Altiplano Central de Los Altos de Chiapas entre los $16^{\circ} 47^{\prime} 15^{\prime \prime}$ de latitud norte y $92^{\circ} 41^{\prime} 21^{\prime}$ de longitud oeste. El clima predominante en el municipio es templado subhúmedo con una temperatura media anual de $13.7^{\circ} \mathrm{C}$. Durante todo el año se distinguen prácticamente dos estaciones: una templada y la otra de bajas temperaturas. Respecto al relieve, el $99.92 \%$ de su superficie se conforma por sierra alta y el resto por valles intermontanos. El $55 \%$ de su suelo es arcilloso poco favorable para actividades agrícolas con una topografía altamente accidentada.

El sector agrícola es clave en la economía de San Juan Chamula por lo tanto se debe de considerar al problema ecológico como una limitante de su productividad. De acuerdo a datos del INEGI (2010) el municipio presenta severos problemas de deterioro ambiental. Según Cayuela (2006), la región donde se ubica la comunidad es una de las zonas con mayores problemas de deforestación a nivel mundial. De 1990 al 2000 la tasa de deforestación en la región fue del $4.8 \%$ anual, tres puntos porcentuales más que la registrada 30 años atrás. Entre las causas que explican este problema se encuentran: la tala de árboles para producir carbón, la creación de nuevos asentamientos humanos y la expansión de la frontera agrícola.

Los datos del último Censo Agrícola, Ganadero y Forestal demuestran un alto grado de erosión en la tierra de labor y una significativa pérdida de fertilidad. En el 2007, el $76.6 \%$ de las unidades de producción con actividad agrícola reportó pérdidas por cuestiones climatológicas y el 37 \% por problemas graves de fertilidad del 


\section{perifèria}

Número 20 (2), diciembre 2015

http://revistes.uab.cat/periferia

suelo. Estos datos demuestran que la expansión de la frontera agrícola ha llegado a su límite; considerando que en el $\mathbf{9 5 . 5} \%$ de la superficie agrícola disponible por las unidades de producción se lleva a cabo alguna actividad agropecuaria o forestal.

Con una producción, no sólo concentrada en el sector primario, sino casi exclusivamente en el cultivo de maíz, frijol y algunas hortalizas, las condiciones ecológicas y geográficas de Chamula han empeorado considerablemente en las últimas dos décadas. El monocultivo en pequeñas parcelas desgasta los nutrientes del suelo y provoca la erosión de la superficie de labor. Es así que la atomización de la tierra ha causado la sobreexplotación del suelo y ha reducido la rentabilidad de la agricultura. Además de la baja productividad agrícola las familias señalan que existe un problema de escasez de leña, causa y efecto de la tala incontrolada. En sus palabras el deterioro ambiental es percibido como resultado de la falta de alternativas económicas.

"[...] Los montes aquí se acabaron por el carbón. Vinieron algunos grupos a enseñar como quemar carbón. Antes 300 años. Antes se lograban ver unos ocelotes. Pero la gente cuando no hay empleo, la gente empieza a trabajar la madera para carbón. Antes no se usaba carbón en Chamula solo en SCLC. Los de Calendaría y Pajarito eran los fabricantes de carbón. En esta zona no se comercializaba la leña. Pero la gente se dio cuenta de que si había venta de carbón, entonces toda la gente empezó a acabar el árbol. En Huixtequi, había grandes árboles, ahora ya no hay nada. El carbón se los acabo. Ahora en Chamula ya lo consumen, pero antes no se consumía".

b) Identificación de las fuerzas productivas

En esta sección se muestra el desarrollo de las fuerzas productivas y de las técnicas con las que cuenta la población para acceder a los medios materiales necesarios para su existencia. Se considera que el grado de desarrollo de las herramientas y las técnicas de producción determina el éxito de las actividades económicas de la comunidad.

En San Juan Chamula, la tierra y la mano de obra son las principales fuerzas productivas; debido a su especialización agraria. En este sentido se destacan los 


\section{perifèria}

Número 20 (2), diciembre 2015

http://revistes.uab.cat/periferia

efectos del incremento poblacional sobre la base material de la comunidad. Según datos oficiales, de 1991 a 2007 se registró un incremento de $30.76 \%$ unidades de producción dedicadas a actividades agrícolas y ganaderas. A pesar de que la pulverización de las unidades económicas representa un ascenso en la atomización de los recursos productivos de la comunidad, se considera que la relación entre el crecimiento de la población campesina y la cantidad de fuerzas productivas dista de ser mecánica. El deterioro ambiental y la presión sobre los recursos naturales son variables correlacionadas que explican los bajos niveles de productividad agrícola.

La explosión demográfica explica el grado de parcelización de la tierra. Sin embrago, a través del análisis histórico se observan que la presión sobre la tierra se debe a distintos factores además de la evolución demográfica. La relación histórica entre crecimiento demográfico y la disponibilidad limitada de recursos productivos en comunidades indígenas en México muestra la complejidad económico-social de la relación entre población y recursos productivos. San Juan Chamula forma parte del problema agrario no resuelto en todo el país. En Chiapas la iglesia católica, el gobierno y algunas organizaciones caciquiles han controlado históricamente el acceso a este recurso. De acuerdo a Villafuerte (2002), la reforma agraria fue demasiado lenta y parcial en toda la entidad afectando considerablemente a la población indígena. En el reparto de tierras intervinieron intereses políticos, contradicciones en el seno de la sociedad local y conflictos entre las mismas autoridades agrarias que resultaron en la exclusión de los indígenas. La entrega efectiva de tierras certificadas a través de las acciones agrarias no se respetó, provocando una serie de conflictos que hasta el día de hoy no están resueltos en la comunidad.

Según datos del Censo Agropecuario y Ganadero del 2007, el municipio cuenta con una superficie total de 26,937.91 hectáreas distribuidas en 15,244 unidades de producción. El $95 \%$ de las familias realizan actividades agrícolas en 25,730.24 hectáreas que representa más del $90 \%$ de la superficie disponible. La distribución de la tierra por régimen de tenencia es: $74.47 \%$ comunales, el 18.64 ejidales y el $6.11 \%$ privadas. Salta a la vista el hecho de que el $97.4 \%$ de la superficie total de las unidades de producción según tipo de derechos sobre la tierra sea propia y a la 


\section{perifèria}

Número 20 (2), diciembre 2015

http://revistes.uab.cat/periferia

vez comunal, debido a que este hecho solo se presenta en zonas étnicas. La propiedad comunal y el uso que se le da a la tierra tienen origen en la época prehispánica Guiteras (1965). Las tierras ejidales se heredan y la posesión se ejerce a través de su uso efectivo. Mientras que la propiedad privada se obtiene mediante la herencia y por la compra, que hasta hace unos años era transitoria.

Una característica esencial de la actividad agrícola en Chamula es su baja productividad, incluso en comparación con el resto de Chiapas. En 2010, con el $63.48 \%$ de la población ocupada en el sector primario, el municipio generó sólo el $1.6 \%$ del valor de la producción total alcanzada a nivel estatal. La siembra en pequeñas extensiones territoriales y en condiciones de temporal explican los bajos rendimientos productivos. De acuerdo a datos del último censo agrícola, el $99.5 \%$ del área agrícola se cultiva en condiciones de temporal. Los ciclos temporales se adaptan a la estación seca de invierno y lluviosa de verano, determinando los rendimientos productivos en función de las condiciones naturales del tiempo.

La baja productividad de Chamula se explica también por la falta de tecnología y modernización en las técnicas y herramientas de producción. Los datos demuestran que la actividad agrícola en la comunidad no es intensiva en capital y que la tecnología empleada es simple y altamente vulnerable a las condiciones climatológicas. Por ejemplo, de las 126 unidades de producción que cuentan con superficie de riego el $87 \%$ emplea básicamente canales de tierra para el aprovechamiento de las precipitaciones pluviales y solo el $10 \%$ cuenta con algún sistema un sistema de microaspersión. Los depósitos para la captación del agua con los que cuenta la comunidad se reducen a bordos $u$ hoyas de agua que mantienen al aire libre; afectando la calidad de la misma. El escaso desarrollo de las fuerzas productivas materiales es un problema fuerte de la comunidad.

Respecto a las unidades de producción que utilizan algún método de tracción en el trabajo agrícola, los datos señalan que el $97 \%$ solo utiliza herramientas manuales y menos del $1 \%$ cuenta con animales de trabajo. Esto quiere decir que prácticamente el trabajo agrícola se basa en la fuerza de trabajo del hombre. El censo agrícola y ganadero del 2007 revela que en todo el municipio no existe ni una sola máquina destinada a la actividad agropecuaria, a pesar de que la localidad este especializada 


\section{perifèria}

Número 20 (2), diciembre 2015

http://revistes.uab.cat/periferia

en el sector primario. Cabe señalar que el uso de algunas máquinas como el tractor también se encuentra limitado por las condiciones del relieve.

En la percepción de los habitantes de la comunidad, la falta de herramientas y máquinas para el desarrollo agrícola es considerada una condición "normal" de los pueblos indígenas pero no por su resistencia al cambio tecnológico sino por la falta de recursos económicos.

"En Chamula " las herramientas del trabajo son las mismas, desde siempre, como no hay dinero. ¿De dónde las vamos a sacar? Además, ¿Aquí donde vas a meter el tractor, sí es todo pendiente?, No, no, a quién le importa el trabajo del campo de los indios, como nosotros, si ya no da dinero como antes" .

"[...] Tiene que haber un cambio ideológico, tecnológico. Cada domicilio en zona rural, pero ahora ya todo supermercado. Todo allá importado. Entonces por eso en Chiapas puede producir tomate, cebolla, y fruta [...]"

"[...] No hay apoyo al campo. Mentira lo que dice el gobierno no hay apoyo. Sí dona tractor ¿a cuanta gente?, no alcanza para todos. Además que donde vas a meter tractor. Aquí no funciona, y eso no lo ve el gobierno, aquí la mula nos ayuda mucho porque la milpa es alta. La horticultura, la floricultura, pero queda poca gente. Ya no hay tierras, todo alambrado cercado".

En el caso de Chamula se constató que el rezago de las técnicas y herramientas de trabajo se debe en gran medida a la falta de créditos productivos. Al hablar con los campesinos de la comunidad se hace evidente que más que una resistencia al cambio tecnológico lo que se vive es una carencia de recursos económicos dirigidos eficazmente al campo. Entre los problemas que enumeran los campesinos para desarrollar actividades agrícolas se encuentra el difícil acceso al crédito. De las 14,436 unidades productivas con actividad agropecuaria solo 99 cuenta con algún crédito oficial y 33 con algún seguro contratado. Es decir, que según datos del último censo agropecuario, el $99.3 \%$ de las unidades productivas efectuó su producción sin ningún crédito y seguro contratados. 


\section{perifèria}

Número 20 (2), diciembre 2015

http://revistes.uab.cat/periferia

El desarrollo de las fuerzas productivas tiene que ver además con los medios intelectuales con los que se cuenta la población para poder extraer eficazmente de la naturaleza lo necesario para su subsistencia. En relación a este aspecto, encontramos que en San Juan Chamula también existe un rezago importante en la capacitación y asistencia técnica en áreas específicas del ámbito agropecuario. En los últimos 10 años, de 14,436 unidades de producción sólo 48 ha recibido capacitación; 47 en temas relacionados a la agricultura y 1 en cuestiones de cría y explotación de animales. Resulta relevante mencionar que del total de unidades económicas que ha logrado acceso a algún tipo de asesoría técnica el $90 \%$ ha solventado los costos con recursos propios. Es relevante porque demuestra la ausencia de programas oficiales que atiendan la problemática del campo en la zona. Asimismo, otro aspecto negativo al que se enfrenta la población de Chamula es la deficiente infraestructura en vías de comunicación que limita la comercialización de los sus cultivos. La gente de los parajes más alejados del centro político del municipio denuncian serias dificultades para vender sus productos tanto en la cabecera municipal como en los mercados de San Cristóbal de Las Casas.

Finalmente, en el siguiente cuadro resumen los principales problemas que declararon tener las unidades de producción para desarrollar su principal actividad económica. El objetivo es dar evidencia del rezago de las fuerzas productivas con las que cuenta la población de la comunidad. 


\section{perifèria}

Número 20 (2), diciembre 2015

http://revistes.uab.cat/periferia

Unidades de producción que reportaron problemas para desarrollar actividad agropecuaria

C

a

u

S

a
Pérdida de fertilidad del suelo

Pérdidas por cuestiones climáticas

9,029

Problemas para la comercialización

$.35 \mathrm{Ha}$.

Infraestructura

insuficiente para la

producción

Superficie erosionada crédito

Dificil acceso al

2,242 Litigios por la tierra

Dificultad para acredita la posesión de la tierra

\section{Problemas: histórico-estructurales}

\begin{tabular}{|c|c|c|c|c|}
\hline Superficie ensalitrada & $.35 \mathrm{Ha}$ & $\begin{array}{l}\text { Infraestructura } \\
\text { insuficiente para la } \\
\text { producción }\end{array}$ & 1,142 & $\begin{array}{l}\text { Alto costo de } \\
\text { insumos y servicios }\end{array}$ \\
\hline Superficie erosionada & $2.10 \mathrm{Ha}$. & $\begin{array}{l}\text { Falta de capacitación } \\
\text { y asistencia técnica }\end{array}$ & 1,085 & $\begin{array}{l}\text { Organización poco } \\
\text { apropiada para la } \\
\text { producción agrícola }\end{array}$ \\
\hline
\end{tabular}

Fuente: Elaboración propia con datos del Censo Agrícola y Ganadero (2007).

Estos datos revelan la problemática económica de San Juan Chamula, considerando que se trata de un municipio especializado en el sector agrícola. Históricamente, la ausencia de alternativas productivas locales, ha forzado a la población a buscar recursos en otros sectores económicos y más allá de los límites geográficos de la comunidad. La producción de artesanías es una de las actividades que ha desarrollado la población a partir de sus fuerzas productivas disponibles.

La exploración etnográfica nos permite advertir que la elaboración de artesanías en Chamula no es la principal fuerza productiva con la que cuenta su población, sino más bien su capacidad organizativa en torno a esta actividad. Hasta 1970 las mujeres producían artesanías con el fin de dejarlas a consigna en tiendas de San Cristóbal de Las Casas. En 1988, su habilidad para organizarse entre ellas resultó en la creación de cooperativas con el fin de vender directamente sus productos no 


\section{perifèria}

Número 20 (2), diciembre 2015

http://revistes.uab.cat/periferia

sólo en San Cristóbal sino fuera de Chiapas. Al día de hoy se constata que son las mujeres de Chamula quiénes controlan el mercado de artesanías en el centro de la ciudad. De acuerdo con Rus y Collier (2002) existen dos sucesos clave en la dinámica de la economía de la comunidad en las que han intervenido directamente las mujeres. El primero se refiere a la producción de bienes tradicionales para el turismo y el segundo tiene que ver con su inserción en el mercado a través de la aplicación de sus conocimientos intelectuales en la producción de maquilas para contratistas en San Cristóbal. Cabe señalar que los artículos artesanales han servido históricamente como moneda de cambio. Hasta el día de hoy se observa el intercambio de artesanías locales por otras de otras comunidades. También se intercambian por otros bienes de consumo final.

c) Las relaciones sociales de producción y sus funciones

En este apartado se analiza la configuración de las funciones de las relaciones sociales de producción. Se presta atención a la forma en que la población de la comunidad se organiza y se relaciona en el proceso productivo; considerando que el entramado de relaciones sociales no gira en torno a la relación: patrón-obrero. Según Castaingts (1979), es difícil establecer clases sociales en el interior de sociedades en las que el modo de producción capitalista no es el dominante; ya que en su determinación se conjuga la plurifuncionalidad y jerarquía de otras estructuras. En sociedades en las que el modo de producción dominante no es el capitalista intervienen relaciones, además de económicas, de parentesco, religión y política.

Es importante señalar que no se habla de una sociedad homogénea sin estratificación social, debido a que esto nos conduciría a un grave error en el que se falsearía la realidad. Se advierten "cambios" en los mecanismos de diferenciación social basados en factores económicos como resultado de la articulación de diferentes modos de producción. Asimismo, se considera la vigencia de factores culturales que intervienen activamente en la organización social del municipio. En principio, las relaciones sociales de producción en la comunidad tienden a satisfacer las necesidades colectivas del grupo; estableciendo mecanismos sociales de cohesión y de igualdad. Sin embargo en la actualidad se observa una clara 


\section{perifèria}

Número 20 (2), diciembre 2015

http://revistes.uab.cat/periferia

conjugación de dos sistemas de diferenciación social. Uno basado en recursos económicos y el otro en factores culturales propios de los Chamulas.

d) Plurifuncionalidad de las estructuras: sistema de cargos

En el caso de San Juan Chamula existe una jerarquía social ligada a un sistema de prestigio, validado a través del trabajo comunal. El sistema de organización colectiva, sistema de cargos, da evidencia de la plurifuncionalidad de las estructuras: religiosa, económica y política. Mediante la asignación de cargos entre los miembros de la comunidad se determinan las funciones de las relaciones sociales que emergen del proceso productivo. A través de la exploración etnográfica se constató que existen tareas de carácter civil, religiosas y políticas, que son resueltas a través de la asignación y el cumplimiento de algún cargo. De acuerdo con Paniagua (2008), la importancia del sistema de cargos rebasa las funciones del padrinazgo o patrocinio en las fiestas y rituales al vincularse con la totalidad de la vida social del grupo. La organización social basada en el sistema de cargos tiene una estrecha relación con la estratificación social de la comunidad, debido a que implica un sistema de valorización expresado a través del prestigio de sus miembros. Por ejemplo, el uso del excedente económico en la compra de bebidas, alimentos y objetos, necesarios en las relaciones sociales de San Juan Chamula; marca cierto nivel de estatus económico entre los miembros del grupo.

Algunos autores mencionan que una parte importante del dinero que el indígena percibe, por su trabajo como asalariado o por las transacciones comerciales, es destinado principalmente al cumplimiento de los cargos que le fueron asignados. En el caso de la comunidad se observó que en las fiestas patronales del municipio las personas con cargo invierten buena parte de sus ingresos en la compra de refresco, bebidas alcohólicas y comida. Además de que gastan una buena parte de sus ingresos en indumentaria nueva. Esto es, el prestigio obtenido a través del sistema de cargos interviene en la organización del proceso productivo. 


\section{perifèria}

Número 20 (2), diciembre 2015

http://revistes.uab.cat/periferia

"[...] ahora en la fiesta, la del carnaval, me tocó cumplir mi cargo. Mi hijo me ayudó y compramos lo necesario para la comida de la fiesta, mi mujer y las otras, de los principales, hicieron el caldo de gallina... pues sí, se gasta pero hay que cumplir [...] La fiesta de San Juan Bautista es más importante, mi ropa es la mejorcita, porque para llevar el bastón de mando hay que ir bien, no nomás así. La fiesta de ahora del 23 de junio es muy importante para todos. [...] en esta fiesta participan las autoridades tradicionales y los oficiales"

"En la fiesta si se gasta pero por eso ya se deja que los mayordomos vendan posch para que así puedamos cumplir [...] aquí no es como en otros lados donde se obliga, por decir, si está lejos mi hijo y soñó que tiene cargo pues ahora sí que lo cumple, pero por voluntad, uno lo sueña".

"Cuando uno ya cumplió, hora sí cuándo ya pasaste desde abajo, hora si puedes ser principal. Cuando ya tienes este rango ahora si puedes tomar decisiones importantes para toda la comunidad"

"[...] yo antes si me enojaba mucho, porque decía y ahora éste si ni ha cumplido su primer cargo y ya quiere mandar aquí en la escuela. Yo primero si lo veía mal pero ahora que veo mi hermano y su familia, ellos si están bien porque él cumplió todos los cargos y se le respeta aquí en el paraje y allá en la cabecera municipal"

El cumplimiento de todos los cargos otorga prestigio; legitimando sociedades estratificadas en función del honor social. Su cumplimiento, cabal, asegura el acceso a los bienes comunales como agua, madera, servicios médicos, religiosos y civiles, entre otros.

"A fuerzas tienes que hacer el servicio. En cada comité por un año y así por ejemplo en el del agua ya nunca pagas agua. Te la dan siempre hasta que te mueras $[\ldots] "$ 


\section{perifèria}

Número 20 (2), diciembre 2015

http://revistes.uab.cat/periferia

Lo mismo ocurre con el acceso a los servicios de la salud, cuando ya sea cumplido el cargo las personas tienen derecho a recibir medicinas y atención médica de por vida. En caso contrario cuando el cargo no es cumplido existen sanciones impuestas por toda la comunidad. La sanción más grave que se encontró fue la privación del servicio no sólo a la persona sino a toda la familia. En sus palabras, cuándo alguien no quiere cumplir con los cargos es porque se trata de hombres y mujeres imperfectos, debido a que solo a través de su cumplimiento se obtiene sabiduría y prestigio.

"cuando la gente tiene cargo es porque lo soñó y de no cumplirlo podía morir. Cuando la gente no cumple con los cargos se les sanciona con una multa de 30,000 pesos para que no se pierda el respeto y la confianza de unos con otros. Además de que no se alteré la gente que sí cumple con el trabajo para todos".

Cabe destacar que hasta el momento en el que se realizó la exploración etnográfica en Chamula todos los cargos y las multas impuestas por incumplimiento se legitimaban a través del acuerdo comunal y del sistema de creencias, sin negar un proceso de desgaste de este tipo de organización. Conociendo la importancia que tiene el prestigio al interior de San Juan Chamula, es correcto afirmar que el prestigio es un hecho clave tanto en los procesos sociales como en los colectivos. La reciprocidad de los miembros de la comunidad es un elemento clave en la organización del proceso productivo a través del contrato diádico que se materializa en el sistema de cargos. Finalmente, es importante hacer énfasis en la plurifuncionalidad de las estructuras que intervienen en el sistema de cargos.

\section{e) Estructura político - religiosa}

Al interior de San Juan Chamula, como en todas las comunidades indígenas, es difícil marcar límites entre las funciones de las estructuras que conforman al modo de producción dominante. Esta situación hace que no sea posible un análisis en partes. Dicho lo anterior, a continuación se analiza la estrecha relación que existe entre la vida política y religiosa de la comunidad, haciendo énfasis en las implicaciones económicas que resultan de esa relación. En 1977 Ricardo Pozas 


\section{perifèria}

Número 20 (2), diciembre 2015

http://revistes.uab.cat/periferia

afirmaba que lo político y lo religioso era formalmente lo más relevante en la estructura de la comunidad. Las instituciones políticas y religiosas ocupan un lugar trascendental en la vida del indígena, asegurando la producción física, la reproducción y la perpetuación del grupo (Pozas, 1977:99-135). A día de hoy podemos afirmar que la vida al interior de Chamula está estrechamente ligada a su sistema de creencias, que a la vez se conjuga y determina al sistema político. En la relación religión-política se revelan aspectos sumamente importantes de la ideología de la comunidad.

La relación entre política y religión se observa a través de la organización de los poderes políticos en el municipio. En la comunidad existen dos niveles de poder: uno legitimado por la comunidad, sin reconocimiento oficial, y otro organizado por las autoridades federales. El primero se conforma por las autoridades tradicionales, consejo de ancianos, del municipio que ya han cumplido con la escalada de cargos religiosos y civiles impuestos por la comunidad. Las funciones del consejo de ancianos son valoradas por la población y se encuentran en una constante interacción con las decisiones del ayuntamiento oficial. La imposición del ayuntamiento oficial ha jugado un rol de intermediación entre Chamula y las autoridades oficiales del Estado.

Las implicaciones económicas de la plurifuncionalidad de las estructuras políticoreligiosas se manifiestan a través de la organización del trabajo comunal, sistema de cargos y de la repartición de los frutos del trabajo. Las fiestas hasta el día de hoy vigentes determinan la actuación económica de los miembros de la comunidad. En San Juan Chamula existe una estrecha relación entre el sistema de creencias y las actividades económicas. Por ejemplo, en el proceso productivo se llevan a cabo ciertos ritos para asegurar la subsistencia física de los individuos y se rezan plegarías que de acuerdo a la gente son necesarias para lograr cosechas abundantes. 


\section{perifèria}

Número 20 (2), diciembre 2015

http://revistes.uab.cat/periferia

Sistema de creencias en San Juan Chamula, plurifuncionalidad de las estructuras

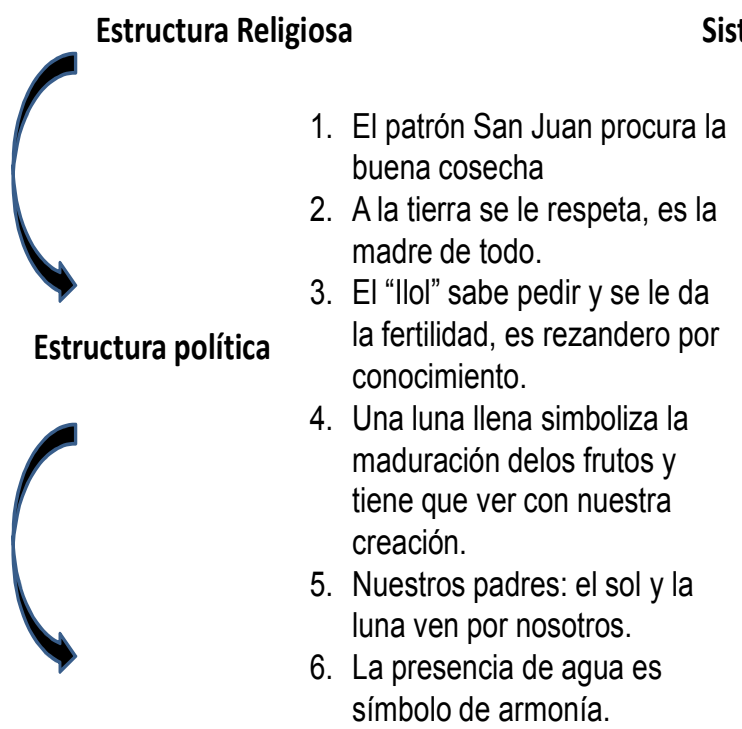

Sistema de creencias

El patrón San Juan procura la buena cosecha

Ala tierra se le respeta, es la

El "llol" sabe pedir y se le da la fertilidad, es rezandero por conocimiento. maduración delos frutos y tiene que ver con nuestra

Nuestros padres: el sol y la luna ven por nosotros símbolo de armonía.

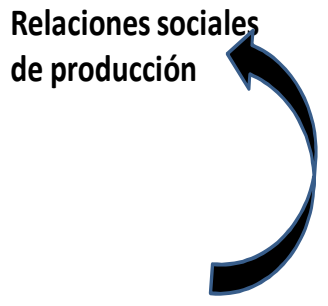

Estructura económica

Representaciones

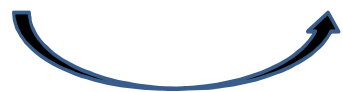

sociales del ecosistema

\section{Conclusiones}

¿Es el concepto de modo de producción el instrumento analítico apropiado para explicar las nuevas realidades del sector rural y los escenarios de confrontación de distintas sociedades? En la presente investigación se validó al concepto modo de producción en la explicación de nuevas realidades y confrontaciones del sector rural en San Juan Chamula. Se comprobó que la operatividad del concepto modo de producción como instrumento analítico no reside en su adecuación formal y estricta al estudio de una determinada sociedad sino a su construcción mediante el estudio de las estructuras sociales específicas.

El entramado de relaciones sociales entre miembros de la comunidad está cambiando y a día de hoy se observan relaciones del tipo patrón-obrero aunque sea fuera de los límites de la comunidad. Es común que los indígenas Chamulas 


\section{perifèria}

Número 20 (2), diciembre 2015

http://revistes.uab.cat/periferia

empleen a gente de su misma comunidad para atender los puestos de comida o de artesanías. Otro aspecto que se advierte es el papel de intermediarios comerciales que han desarrollado los chamulas con otros indígenas de la entidad. Retomando la idea de Catsingts (1979) referente a que cada modo de producción tiene formas exclusivas de explotación a continuación se presentan fragmentos de entrevistas que dan cuenta de cómo la misma población percibe este proceso.

"[...] llevo aquí un año siete meses, me gusta el trabajo con don Juan. Yo nunca he trabajado en San Cristóbal prefiero aquí, la mujer de Juan es buena y así no me gastado mi paga para cuándo voy a mi casa. Estando aquí uno no gasta en comida ni renta, aquí yo vivo como hija. Eso sí con trabajo pero también con paga. Mi prima ella sí que esta allá en Jovel en una tienda pero le va mal apenas si puede con la renta del cuarto y todavía aguanta que la vean mal, yo siempre digo que es mejor aquí con nuestra gente $[\ldots] "$

"[...] en el mercado pagan a 800 y aquí en la tortillería más mejor, un poco pero más bien $[\ldots]$ "

"Aquí se trabaja muy duro pero aquí no me siento tan sola como en Mérida, aquí no hace tanto calor y no extraño tanto a mi mamá. La Dominga deja a mi mamá quedarse en su casa cuándo me visita, es buena la Dominga [...]" "[...es que ando caminando desde harto y no he vendido nada, a mí no me gusta dejar mi blusa con la Chamula pero es quién te la paga ya a esta hora ella se hace cargo "

Como resultado de los flujos migratorios también se están presentando cambios importantes en la estructura social de la comunidad. A partir de que los flujos migratorios se han transformado traspasando los límites nacionales se observa una tendencia cada vez mayor a partir de los ingresos. Los casos exitosos que han regresado a la comunidad están generando una concentración mayor de recursos materiales a la vez que incitan a otros miembros de la comunidad a salir. El crédito 


\section{perifèria}

Número 20 (2), diciembre 2015

http://revistes.uab.cat/periferia

es uno de los mecanismos más activos en la transformación de los lazos comunitarios.

"[...] aaaa mis hijos se fueron al norte, cómo cuáles negocios, a ver dime. A bueno. Solo tenemos un changarrito aquí, la tortillería nada más. Dos puestos en el mercado, yo doy trabajo a 2 muchachas en el mercado, una muchacha en la tienda, una muchacha en la tortillería y dos más. O sea que son 7, trabajan muchachos y muchachas"

"[...] mi hijo ayudó a su primo y así ahí en la escuela del bachiller ahí les prestó el tío de Pascual,[...] cobran como el $15 \%$ de interés [...]"

Finalmente, se cierra este documento con dos ideas puestas a discusión. La primera, el rechazo a establecer modos de producción homogéneos y estáticos. Las comunidades indígenas campesinas no son unidades aisladas del resto del sistema capitalista y tampoco corresponden con sistemas precapitalistas. Esto es, se rechaza la idea de una evolución lineal de las sociedades. La segunda, en México coexisten diferentes modos de producción y por tanto no existe una sociedad homogénea.

\section{Bibliografía}

Aguirre-Beltrán, Gonzalo (1970). El Proceso de aculturación y el cambio sociocultural en México, Comunidad, Instituto de Ciencias Sociales, Universidad Iberoamericana, México.

Aguirre-Beltrán, Gonzalo (1973). Regiones de refugio: el desarrollo de la comunidad $y$ el proceso dominical en mestizoamérica, Instituto Nacional Indigenista, México.

Bartra, Armando (1979). La explotación del trabajo campesino por el capital, Macehual, México.

Bartra, Armando (1979). Polémica sobre las clases sociales en el campo mexicano, Editorial Macehual, México.

Bartra, Armando (1982). "Perspectiva del movimiento campesino" en Revista de la UAG, núm. Extra 2, Chilpancingo, pp. 5-19. 


\section{perifèria}

Número 20 (2), diciembre 2015

http://revistes.uab.cat/periferia

Bartra, Armando (2012, septiembre 9). Reabriendo el debate latinoamericano sobre el campesinado como clase social. Entrevista por Leyva Remón. Recuperada de http://www.rebelion.org/noticia.php?id=156463

Bartra, Roger y Otero, Gerardo (2008). "Crisis agraria y diferenciación social en México", Revista Mexicana de Sociología, Vol.50, No.1. 50, pp.13-49. DOI: $10.2307 / 3540502$

Bartra, Roger (1974). Estructura agraria y clases sociales en México, Era, México.

Bartra, Roger (1975). Marxismo y sociedades antiguas, Grigalbo, México.

Bartra, Roger (1977). El poder despótico burgués: Las raíces campesinas de las estructuras políticas de medición, Peninsula, Barcelona.

Bartra, Roger (1982). Campesinado y poder político en México, Era, México.

Castaingts, Juan (1979). Articulación de modos de producción, El Caballito, México.

Castaingts, Juan (2013,2 de mayo). Modos: productivos, de pensar y de actuar. Así Vamos. Crisol Plural, pp.

Cayuela, Luis (2006). "Deforestación y fragmentación de bosques tropicales montanos en los Altos de Chiapas, México. Efectos sobre la diversidad de árboles" en Ecosistemas, $15 \quad$ (3) pp. 192-198. Disponible en: http://www.revistaecosistemas.net/articulo.asp? Id =438

Chayanov, Alexander (1974). La organización de la unidad económica campesina [1925] Ediciones Nueva Visión, Buenos Aires. DOI:10.2307/3466282

De Teresa, Ana Paula (1996). "Una radiografía del minifundio: población y trabajo en los valles centrales de Oaxaca 1930-1990", en Hubert Carton de Grammont (coord.), La sociedad rural frente al nuevo milenio, Plaza y Valdés, México, pp. 189242.

Díaz-Polanco, Héctor (1976). "La economía campesina y el impacto capitalista. Un caso mexicano", en Rodolfo Stavenhagen (ed.), Capitalismo y campesinado en México: estudios de la realidad campesina, SEP-INAH, México pp. 69-96.Godelier, Maurice (1974), Marxismo, antropología y religión México, Roca.

Godelier, Maurice (1975). Racionalidad e irracionalidad en economía, México, Siglo XXI.

Guiteras, Calixta (1965). Los peligros del alma. Visión del mundo de un tzotzil, Fondo de Cultura Económica, México.

Kochanowicz, Jacek (1989)."La teoría de Chayanov y el punto de vista polaco respecto a la economía campesina" en AREAS, Revista Internacional de Ciencias Sociales, núm. 11, pp 109-122.

Kroeber, (1948). Anthropology, New York. 


\section{perifèria}

Número 20 (2), diciembre 2015

http://revistes.uab.cat/periferia

Lenin, Vladímir ([1899] 1974). El desarrollo del capitalismo en Rusia. El proceso de la formación del mercado interior para la gran industria. Moscú.

Marx, Karl (1859). Prefacio de Contribución a la crítica de la economía política México, Siglo XXI.

Meillassoux, Claude ([1975] 1979). Mujeres, Graneros y Capitales: economía doméstica y capitalismo, Siglo XXI Editores.

Palerm, Ángel (1976a). Antropología y marxismo, Nueva Imagen. México

Palerm, Ángel (1976b). "Sobre la formación del sistema colonial en México: notas para una discusión", Mímeo, CISINAH.

Palerm, Ángel (1978). "Antropólogos y Campesinos", en Antropología y Marxismo. Editorial Nueva Imagen, México, pp 196

Palerm Ángel, (1980). Antropología y marxismo, Instituto Nacional de Antropología e Historia, Centro de Investigaciones Superiores, Nueva Imagen, México, D.F.

Palerm, Ángel (1986). Modos de producción y Formaciones Socioeconómicas, Ediciones Gernika, México.

Paniagua, Jorge (2008). "De los pueblos indios a la ficción antropológica: los sistemas de cargos en la etnografía de los altos de Chiapas: Antecedentes, Balance y Perspectivas", en Pueblos y fronteras digital, junio-noviembre, México, pp.

Pozas, Ricardo (1977). Chamula, Instituto Nacional Indigenista, México.

Redfield, Robert (1930). Tepoztlán, a Mexican village: A study of folk life. University of Chicago Press.

Redfield, Robert (1948). Folk Cultures of the Yucatán. Chicago: University of Chicago Press. DOI: $10.2307 / 2262507$

Redfield, Robert ([1956]1989). The little community and Peasant society and culture. Chicago: University of Chicago Press.

Rus, Jan y Collier, George (2002). "Una generación en crisis en Los Altos de Chiapas: Los casos de Chamula y Zinacantán, 1974-2000", en Shannan L. Mattiace, Rosalva Aída y Jan Rus, Tierra, Libertad y autonomía: impactos regionales del zapatismo en Chiapas, CIESAS, pp. 157-199.

Stavenhaguen, Rodolfo (1968). "Clases colonialismo y aculturación", Ensayos sobre las clases sociales en México, Editorial Nuestro Tiempo.

Stavenhagen Rodolfo (1969). Las clases sociales en las sociedades agrarias, Siglo XXI, México. 


\section{perifèria}

Número 20 (2), diciembre 2015

http://revistes.uab.cat/periferia

Stavenhagen, Rodolfo (1976). Capitalismo y campesinado en México: Estudios de la realidad campesina, México. INAH.

Villafuerte, Daniel (2002). La tierra en Chiapas: viejos problemas nuevos, Plaza y Valdés, México.

Warman, Arturo (1972). Los campesinos: hijos predilectos del régimen, Nuestro

Tiempo, México.

Warman, Arturo (1980). Ensayos sobre el campesinado en México. Editorial Nueva imagen. México.

Wesserstrom, Robert (1980). Ingreso y trabajo en los Altos de Chiapas: El caso de San Juan Chamula, San Cristóbal, Chiapas, Centro de Investigaciones Ecológicas del Sureste.

Wolf, Eric (1971). Los campesinos, Labor, Barcelona.

Wolf, Eric (1973). Las luchas campesinas del siglo XX. Siglo XXI.

Wolf, Eric (1981). "Comunidades corporativas cerradas de campesinos en Mesoamérica y Java Central [Southwestern Journal of Anthropology, vol. 13, No. 1, 1957] Llobera, J.R. (ed.): Antropología económica. Estudios Etnográficos. Barcelona: Anagrama. 